cortical visual organization but the study offers a simple and practical method of treatment that is worthy of trial in a larger number of younger subjects. The results could be different in children from those in adults, aged $18-25$, used in this study (See PED NEUR BRIEFS $\underline{1}(1): 5$ )

\title{
TRICYCLIC ANTIDEPRESSANTS AND ATTENTION DEFICIT DISORDER
}

A review of the literature concerning imipramine and other tricyclics in the treatment of attention deficit disorder (ADD) is presented from the Dept Psychiatry, Univ. Texas Health Sci Cntr, 7703 Floyd Carl Drive, San Antonio, TX 78284. Imipramine was the drug of choice in a subgroup of children with ADD who had higher levels of anxiety or depression or both. Methylphenidate was superior to imipramine in the treatment of ADD overall.

The author conciudes that: (i) reports of imipramine as the arug of choice in ADD are unjustified, (2) stimulants are the first choice and imipramine second, (3) children with ADD complicated by anxiety and/or mood disturbance may respond better to imipramine than to methylphenidate, (4) doses of imipramine are not superior to higher doses and $<\mathrm{lmg} / \mathrm{kg} /$ day is ineffective. (Pliszka SR. J Amer Acad Child Adol Psychiat, 1987; 26:127-132).

COMMENT: My own experience, without the benefit of double-blind controls, would place methylphenidate as the drug of choice in ADD with hyperactivity uncomplicated by anxiety. As a pediatric neurologist, I am reluctant to prescribe imipramine for ADD with anxiety or depression (1) because of the dangers of cardiac arrhythmia with accidental poisoning and (2) my inability to evaluate properly its effects on the associated psychiatric symptoms. It is my opinion that this treatment should be followed by our colleagues in child psychiatry. Since imipramine has fallen out of favor in the treatment of nocturnal enuresis which sometimes complicates ADD, I no longer use the drug in my practice. For those patients with ADD and secondary anxiety reactions, I prefer thioridazine (Mellaril) if medication is required.

Drugs in the management of ADD with hyperactivity are controversial and they play a larger role in the USA than in England, whore dictary modification is in voguc. With incrcascd awurcnces of the problem by educators and more individualized attention to associated learning disabilities, the need for medication has lessened appreciably. Behaviour modification and other psychological approaches to deal with hyperactivity are often sufficient to deal with anxiety caused by frustration and to lessen the impulsivity.

The present article emphasizes the need to correctly classify children with ADD into groups with or without conduct and anxiety disorders when evaluating drug effects. Werry JS et al, writing in the same journal, find that the co-existence of $A D D$ and conduct disorder increases the degree of disability and suggest that ADD with hyperactivity is a cognitive disorder, possibly of neurodevelopmental origin. ( $\underline{\mathrm{J}}$ Amer Acad Child Adol Psychiat. 1987; 26:133-143). 